\title{
Ni rara, ni extraordinaria: política y corporalidad en Eva Perón*
}

\author{
Karina Elizabeth Vázquez** \\ "Oímos del puro labio que entreabrió \\ cuando dijo: \\ 'En las profundidades aún no me han \\ callado'". \\ Venturini (2014), "88 Eva Alfa y Omega”.
}

Resumen: Este ensayo analiza imágenes indiciales y representaciones icónicas de Eva Perón a partir de un enfoque que combina las nociones de corporalidad y afectividad con las teorías de la imagen fotográfica propuestas por WJT Mitchell, Roland Barthes y Susan Sontag. La tesis principal de este trabajo propone revisar los mitos sobre la figura de Eva Perón a partir de un análisis de su corporalidad y su relación con el imaginario pre-peronista en torno a la mujer, la política, la belleza y el consumo.

Palabras clave: Eva Perón, mito, política, belleza, Argentina.

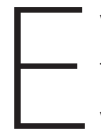
va Perón es una de las figuras de la historia política y social argentina más estudiada y ficcionalizada. Desde los campos de la crítica, la literatura, las artes visuales y la plástica se han abordado los hechos más significativos de su vida, así como sus rasgos personales más icónicos. Con mayor o menor apego a las referencias históricas, estos discursos han explorado los dos relatos fundantes sobre su persona: el mito blanco, que la santifica presentándola como una madonna entregada a lucha por la justicia social, y el mito negro, que envilece su figura mostrándola como una mujer arribista, manipuladora y megalómana ${ }^{1}$. Mediante el trabajo con el lenguaje y las imágenes, los discursos críticos y creativos han dado cuenta de las formas en que a lo largo de la historia ambas figuraciones se han ido reactualizado, a punto tal de que la representación comienza a ocupar el lugar de lo real y se convierte en reemplazo de la historia misma.

Tanto estos mitos contrapuestos generados durante su corta vida, como las figuraciones icónicas surgidas posteriormente a su muerte (el hada buena de los pobres, la madre protectora del pueblo, la política feroz de los discursos en el balcón y la revolucionaria irredenta de los jóvenes setentistas), condensan tropos socioculturales que hablan más de la (de)construcción de una idea de nación y de formas de

* Este ensayo es
el resultado de
reflexiones de
larga data sobre la
iconografía de Eva
Perón a partir de
varias experiencias.
En primer lugar,
la lectura de
numerosos ensayos
críticos sobre
la figuración de
su cuerpo en la
literatura, las artes
visuales y el cine,
que se han publicado
en la última década
y media. En Segundo
lugar, las reflexiones
que me despertaron
las conversaciones
con mis estudiantes
del seminario
sobre la figuración
del cuerpo de Eva
Perón dictado en
el semestre de
otoño de 2013,
en la Universidad
de Alabama, en el
cual analizamos
extensamente el
interesante trabajo
de Paola Cortés
Rocca y Martín
Kohan (1998),
Imágenes de vida,
relatos de muerte.
Eva Perón: cuerpo
y política. En tercer
lugar, el seminario
especial sobre
transformaciones
en la corporalidad
de Eva Perón que
tuve oportunidad
de dictar durante
noviembre de 2014
en la Universidad
de Masaryk, en la
República Checa.
A los estudiantes y
colegas les agradezco

* Este ensayo es el resultado de larga data sobre la iconografía de Eva varias experiencias. En primer lugar la lectura de críticos sobre la figuración de que se han publicado lugar, las reflexiones que me despertaro quenveriones del seminario Perón dictado en el semestre de ño de 2013 cual analizamos de Paola Cortés Rocca y Martín relatos de muerte. Eva Perón: cuerpo y política. En terce especial sobre transformaciones de Eva Perón que tuve oportunidad de dictar durante colegas les agradezco 
el ávido interés por el tema y la creatividad con que lo abordaron dentro y fuera del salón de clases. En cuarto lugar, agradezco a Laura Covello, directora de la Biblioteca del Museo Eva Perón, quien a cada pedido de material visual y bibliografico no solamente respondió con una gran calidez, sino que además lo hizo aportando su conocimiento sobre el tema. Por último, le agradezco a Andrés Avellaneda su exhaustiva y enriquecedora lectura.

**Karina Elizabeth Vázquez es socióloga (Universidad de Buenos Aires) y doctora en literatura latinoamericana (University of Florida, EE.UU). En la actualidad es directora del Programa de Aprendizaje con la Comunidad en el Departamento de Estudios Latinoamericanos, Latinos e Ibéricos de la Universidad de Richmond (Virginia). Es autora de: Fogwill: realismo y mala conciencia (Edhasa/ Circeto, 2009); Aprendices, obreros y fabriqueras: el trabajo industrial en la narrativa argentina del siglo XX (Editorial Biblos-Crítica y Teoría Literaria, 2013); y, junto a Grazyna Walczak (Valdosta State University) y Claudia García (University of Nebraska - Omaha) es co-editora de ejercicio de la democracia, que de una mujer cuya mayor virtud histórica seguramente ha sido la de (de)construirse a sí misma en la medida en que lo político se hacía carne en su ser. Quizá sea esto aquello que explique la abundancia de estudios que indagan diversos aspectos de su vida. Sin embargo, podría observarse también que la causa de esta perenne curiosidad por su figura tal vez no sea la sospechada existencia de una extraordinaria naturaleza, sino la necesidad de comprender qué es aquello que en distintas coyunturas ideológicas y políticas motiva nuestra mirada sobre este complejo personaje histórico y político.

\section{Cuestiones metodológicas: epistemes y miradas}

En Eva. Alfa y Omega, Aurora Venturini (2014), escritora, colaboradora y amiga de Eva Perón, sitúa en la infancia de ésta algunos de los rasgos que durante su vida política alcanzaron mayor magnitud y proyectaron su imagen póstuma. Escribe Venturini:

[l]a palabra estridente, rueda de fuego que aumentaría en la adultez. En la cuarta parte del siglo veinte, para algunos oídos, atrevida y chocante. Los jóvenes comenzaron a oírla con interés que se convirtió en adhesión a una contemporánea futuralidad; su liderazgo había despertado en un baldío donde jugaba con Herminda un juego peligroso de pobres contra ricos; ella estaba con los pobres... (Venturini, 2014: 23).

El tono descarnado y siempre extravagante de Venturini la aleja de lo hagiográfico y al mismo tiempo le permite mostrar algo que está más allá de Eva Perón. Es algo que trasciende la historia de su nombre, su cuerpo y sus figuraciones, pero que al mismo tiempo no puede concebirse, al menos en la historia argentina, sin pasar por el filtro de su existencia y de su corporalidad.

La autora alude a la capacidad persuasiva de Eva Perón con la expresión futuralidad. El sema "baldío" insinúa dos significados, uno literal y otro simbólico. El primero refiere obviamente al páramo rural en el que Eva y su hermana jugaban y donde Eva hacía oír su estridente voz, mientras que el segundo referiría de manera paradójica no tanto a un espacio despoblado, sino al locus social futuro en el que su cuerpo sería el agenciador de los Ilamados "derechos de segunda generación" ${ }^{2}$. Es decir, el cuerpo de Eva Perón no puede ser observado como algo independiente de la exclusión social de la Argentina oligárquica de la década del treinta, ese locus que su acción concreta llenó de sentido de inclusión y derechos sociales, que más tarde formó parte de la Constitución de 1949 (Baschetti 2013: 14) y que, una vez derogada 
ésta por el golpe militar de 1955, se transformó en mera futuralidad. Esta referencia inicial a Venturini tiene por objeto señalar la necesidad de conectar desde la perspectiva crítica la imagen con la palabra, la retórica visual con la discursividad verbal y la corporalidad con la acción, para dar cuenta de las inscripciones histórico-culturales y sociales encarnadas en la corporalidad de Eva Perón ${ }^{3}$.

Este ensayo se inscribe metodológicamente dentro de los estudios visuales y de la percepción. En este sentido, vale la pena hacer dos aclaraciones de corte epistemológico. La primera se refiere al tema de lo emocional, ya que de un tiempo a esta parte las llamadas teorías del afecto han permeado las lecturas críticas sobre la historia social y cultural latinoamericana, especialmente en los estudios sobre el papel de las imágenes en la propaganda política y en la formación de una cultura de consumo entre los sectores asalariados durante el peronismo. En este ensayo, además de ser una dimensión articulada con otras variables, como las económicas y las políticas, lo emocional es una categoría de comprensión de los textos culturales y, especialmente, de la interacción entre las retóricas visuales y los discursos verbales. Entiendo lo emocional como una variable conectada con lo racional y con función cognitiva, es decir, como una dimensión estructuralmente relacionada con el terreno del pensamiento y de la discursividad verbal. Desde esta perspectiva, emoción y razón se encuentran relacionadas, así como también lo están la experiencia y el lenguaje, el pensamiento y la acción. El afecto constituye una serie de prácticas que ponen de manifiesto modos de vivir, ya que las

[...] emotions occur in everyday life, understood as richly expressive aesthetic feeling-cum-behavior of continual becoming that is provided chiefly by bodily states and processes... (Thrift, 2004: 50).

De este modo, saber o conocer son fenómenos paralelos a las percepciones creadas por los encuentros del cuerpo con el entorno, por lo que pensar, hacer y sentir se encuentran interrelacionados.

La variable emocional ha sido también considerada por teóricos de lo visual como W. J. T. Mitchell (1986; 1994), quien sostiene que el carácter emocional de la imagen no es un a priori o una esencia diferenciadora respecto de la palabra, sino un elemento común a ambas, imagen y palabra, y se encuentra operando de manera cognitiva y perceptiva en la generación de imágenes mentales y en la recepción de imágenes indiciales, aunque la interpretación de ambas (figuraciones mentales e imágenes indiciales), ponen en funcionamiento sistemas decodificadores diferentes. En estos, el papel del discurso verbal no es del todo determinante frente al conjunto de procesos sensoriales. El poder político y significante de las imágenes
Insomne pasado: lecturas críticas sobre Latinoamérica colonial. Un homenaje a Félix Bolaños (F\&G 2016).

1. La bibliografía sobre los mitos en torno a la figura de Eva Perón es abundante $y$ valiosa. De entre los numerosos trabajos monográficos y volúmenes editados, probablemente la compilación realizada por Marysa Navarro sea una de las más completes al respecto, recogiendo una variada gama de enfoques desde el cine hasta la literatura y el teatro.

2. Como derechos de segunda generación se entiende a aquellos que refieren a la ancianidad, la seguridad social, las condiciones laborales dignas, la infancia, la soberanía política y económica que, como resultado de la ayuda social y de la transformación de ésta en justicia social, tienen un impacto generacional.

3. Los términos cuerpo y corporalidad tienen distinto significado. El primero alude a una realidad con cierto carácter objetivo, mientras que el segundo refiere al campo subjetivo. La corporalidad se sale del cuerpo para manifestarse en las relaciones con los objetos y el espacio, exponiendo o dando cauce a experiencias 
y vivencias (LópezIbor Aliño, 1974; Montenegro Medina, Ornstein Letelier \& Tapia llabaca, 2006). Aunque se ha señalado que la corporalidad es una abstracción y no una percepción (López-Ibor Aliño, 1974), en este ensayo tal división no es considerada como un absoluto, puesto que las emociones encarnan en el cuerpo con un consecuente correlato neurológico y cognitivo,

formando parte de las figuraciones y lecturas de la realidad que hacemos, por lo que eliminar la parte perceptiva de la corporalidad podría ser algo arriesgado para el abordaje de sus significaciones en el imaginario social.

\section{La consideración} de lo afectivo no debería quedar reducida a esquemas de comprensión binarios del tipo razón vs. emoción. Estos propician lecturas en las que la explicación de fenómenos sociopolíticos como el populismo (dentro del cual se ha encuadrado al peronismo) se centra en la base supuestamente emocional de éstos. Un ejemplo podemos verlo en la siguiente afirmación de Roger Bartra, quien sostiene que "[e]n el centro de la cultura populista hay, más que un conjunto articulado de indiciales no reside en el supuesto valor de aquello que capturan, así como tampoco el poder de la retórica verbal radica tanto en la literalidad (como sí reside en la dinámica entre denotación y connotación), sino en el "sensorium" (Williams, 1974) que sostiene o da "cuerpo" a la imagen o discurso como resultado de una práctica social inscrita también en las miradas; es decir, el poder de las fotografías reside en su capacidad de interpelar emocional e intelectualmente tensando los modos de ver establecidos, y el poder del habla en la capacidad de "enfocar" o dirigir la mirada. La fotografía entonces forma parte de una relación dialéctica entre mirada e imagen que no es explicativa de los hechos, sino que puede ser cuestionadora del presente. Por otra parte, desde los estudios de la fenomenología de la percepción (Merleau-Ponty, 2002) y del tacto, se observa que en la interacción de los sentidos (Linden, 2016), el estímulo desatado por la imagen indicial produce instancias de extereopercepción e intrapercepción que recorren mapas sensoriales que remiten a experiencias dadoras de sentido y, por ende, a codificaciones socioculturales. Esta ubicuidad de lo afectivo señala entonces que no debe descartarse su presencia dentro del propio marco epistemológico desde el cual se imparten las interpretaciones sobre un determinado objeto de estudio ${ }^{4}$.

La segunda consideración epistemológica sobre lo emocional retoma lo propuesto por Eva Illouz (1997; 2007; 2012) en sus distintos estudios sociológicos sobre la relación entre los discursos sobre el amor y la construcción de la identidad bajo la insignia del capitalismo. La socióloga sostiene que lo emocional no es una acción per se, sino

...the inner energy that propels us toward an act, what gives a par-
ticular 'mood' or 'coloration' to an act. Emotion can thus be defined
as 'energy-laden' side of action, where that energy is understood to
simultaneously implicate cognition, affect, evaluation, motivation,
and the body. Far from being pre-social or pre-cultural, emotions
are cultural meanings and social relationships that are inseparably
compressed together and it is this compression which confers on
them their capacity to energize action. What makes emotion carry
this 'energy' is the fact that it always concerns the self and the re-
lationship of the self to culturally situated others... (IIlouz, 2007: 3).

Por consiguiente, tanto el objeto de estudio de este trabajo, como el marco desde el cual se formulan sus interpretaciones están vinculados con lo emocional, aunque el abordaje de Eva Perón a partir de imágenes indiciales nos habla de algo más que su supuesta manipulación afectiva de las masas, y nos lleva a identificar los procesos sociales encarnados en su cuerpo. Por esta razón, parto de la década del treinta -momento de difusión de una imagen femenina urbana asociada al consumo de productos de belleza, vinculados a su vez con la cultura masiva de la radio y el cine-, 
de la cual surgen las primeras imágenes públicas de Eva, para llegar a la primera década del nuevo milenio, en la que las crisis de los modelos neoliberales y de las políticas de exclusión conforman el contexto de nuevas miradas sobre su persona.

Los estudios sobre la iconografía peronista, especialmente sobre la figura de Eva Perón, se encuentran enmarcados en el renovado interés por comprender algo mucho más urgente que la supuesta naturaleza irracional del peronismo y el resurgimiento de los populismos en la región hacia los primeros años del nuevo milenio. Al indagar sobre las formas en las que se articuló históricamente nuestro presente a partir de la lectura de las significaciones políticas, culturales y sociales del cuerpo y la corporalidad de Eva Perón, tanto los estudios críticos, como las propuestas creativas, llevan a cabo una exploración de la configuración de la mirada social e individual. La reciente publicación de Roberto Baschetti (2013), Eva Perón. Registros bibliográficos, ofrece una exhaustiva nómina de los estudios críticos sobre esta figura. Es de notar que el texto se encuentra acompañado por fotografías de Eva Perón en distintas instancias privadas y públicas, y por ampliaciones de estas imágenes en las que se destacan ciertos aspectos de su corporalidad, tales como los gestos, la mirada, la postura, el rostro, la sonrisa y los brazos. Esta triple composición de datos bibliográficos, fotografías y ampliaciones no solamente exhibe el continuo interés por su figura y sus significaciones, sino que homologa la historia del personaje con la historia de las miradas que se han vertido sobre él. Podría pensarse así que la composición tiene el objetivo de equiparar discurso verbal con retórica visual para re-enfocar el ojo del lector. Las imágenes también dicen algo, tal vez un contenido aún no abordado por la gran profusión de palabras. En un sentido, la composición verbal y visual del registro de Baschetti expone la futuralidad de la que habla Venturini, no ya como la fuerza política perceptible en esa Eva niña, identificable más tarde en la mujer política, sino como una forma pragmática de entender el mundo inscrita en su corporalidad. Esta fuerza política resuena con un imaginario social que hacia las décadas del treinta y del cuarenta la albergaba como una posibilidad cultural futura.

Desde mi punto de vista, las constantes reflexiones críticas, históricas y artísticas sobre el cuerpo y la corporalidad de Eva Perón constituyen un indicador de interrogantes que exceden al objeto en sí. Ni sus imágenes fotográficas, ni sus infinitas figuraciones literarias y visuales develan la existencia de una sustancia única en su persona que explique su efecto sobre los otros. Los discursos políticos, culturales y críticos han confinado la recepción masiva de la figura de Eva al territorio de las emociones, entendiéndolo fundamentalmente como la expresión de lo irracional. Este tipo de lecturas terminan por encuadrar las acciones de Eva en un tipo de política institucional centrada en el paternalismo, entendiendo su corporalidad como un puente directo entre el estado y el pueblo. Ahora bien, en tal asociación la noción ideas, un ramillete de emociones dirigidas a curar la herida colonial y a exaltar la identidad nacional [...] las emociones se ligan a poderosas ideologías nacionalistas..." (Bartra, 2012: 23). Si bien esta observación es acertada, la comprensión de las realidades políticas y sociales latinoamericanas quedaría subsumida en un antagonismo en el que el mundo de las ideas es asaltado por el de las pasiones, perpetuando una vez más en el campo de lo epistemológico el binarismo civilización y barbarie. Estas lecturas aportan miradas interesantes, pero dejan de lado aspectos relacionados con el populismo que explicarían con un mayor alcance la naturaleza de la relación entre la democracia y el Estado como articulador de las interpelaciones políticas y regulador social (Rosano, 2010: 241). 
de Estado de bienestar que se presenta no es la del Estado garante de los derechos, sino la del Estado proveedor. Esta asociación es coherente con un tipo de figuración en que la corporalidad de Eva queda reducida a la dádiva y, por ende, a la manipulación emocional. Esta recepción descarta el vínculo entre la corporalidad de Eva Perón y un imaginario social que ya concebía esa figuración como una posibilidad cultural en el plano colectivo.

La interpretación de Beatriz Sarlo sobre la figura de Eva Perón en gran medida sintetiza esto al sostener que, a modo del aura benjaminiana, el cuerpo de Eva Perón condensa las virtudes del peronismo al personalizar su legalidad. Para la crítica, de esta manera los valores democráticos ya no se encuentran en el espacio vacío de la accesibilidad, sino que quedan emplazados en una corporalidad venerable:

\begin{abstract}
Como en una monarquía ... [e]l cuerpo de Eva da cuerpo a la sociedad de los peronistas (y también a esa otra sociedad, la de los opositores, que la odiaban hasta la muerte). Antes que una ideología, antes que un sistema de ideas, el peronismo fue una identificación (Sarlo, 2003: 91-92).
\end{abstract}

La afirmación de Sarlo es refutada por las lecturas que incorporan epistemológicamente la relación entre emoción y razón, entre imagen y discurso verbal, y entre mirada y construcción de las formas de mirar como dimensiones inseparables de la comprensión de los significados del cuerpo y la corporalidad de Eva Perón. Esto me permite formular que ideología e identificación no son ámbitos separados, como se observa en la interpretación de Sarlo, sino dimensiones profundamente vinculadas a partir de la convergencia que se produce en la elaboración del pensamiento entre lo emocional y lo racional, y entre los códigos de representación visual y los de producción verbal.

5. Al respecto, vale mencionar el trabajo realizado por las primeras dirigentes del peronismo (19491955) a partir de la formación del Partido Peronista Femenino, mujeres que en su función de delegadas y subdelegadas -bajo la dirección de Eva Perón-, ingresaron a la actividad política en distintas regiones del país (Barry, 2011).

\section{Propósito:}

\section{algo más que imágenes de un ícono}

Aquí me interesa resaltar el hecho de que tanto en la perspectiva literaria, como en la plástica, el interés por la identificación de una esencia extraordinaria en su cuerpo ha cedido paso a la observación de sus múltiples figuraciones. Propongo ver en la corporalidad de Eva Perón la figuración de un cuerpo femenino que se asume como locus político, y cuya estampa es la capacidad de agenciamiento a partir de una inteligencia que no prescinde de lo emocional ${ }^{5}$. Desde esta perspectiva, su cuerpo deja de erigirse como una esfinge para pasar a ser un prisma de experiencias pasadas y futuras de otras mujeres. En este análisis se observará que en la composición de 
series fotográficas se revelan figuraciones del cuerpo femenino en general, y del de Eva en particular, que resultan de procesos sociales específicos, de los cuales su corporalidad es la manifestación de un locus político inédito en su momento. Aquello que ha vuelto disonante su figura no es ninguna rareza presente en su cuerpo o en su naturaleza psíquica, sino una corporalidad que encarna procesos de significación social pretéritos y futuros. Para esto, sigo lo propuesto por W. J. T. Mitchell (1994) en sus diversos estudios sobre la relación entre imagen y discurso. Su planteo general es que así como hacia fines de los sesenta Richard Rorty introdujo desde el ámbito de la filosofía el llamado "giro lingüístico", que condujo a una revisión epistemológica de las ciencias sociales y las humanidades, en la etapa inmediatamente posterior al auge de las miradadas postmodernas, es decir, hacia mediados de los noventa, es necesario comenzar a hablar de un "giro visual". El autor entiende que este cambio de perspectiva no busca retornar a la mimesis

... copy or correspondence theories of representation, or a renewed metaphysics of pictorical "presence": it is rather a postlinguistic, postsemiotic rediscovery of the picture as a complex interplay between visuality, apparatus, institutions, discourse, bodies, and figurality. It is the realization that spectatorship (the look, the gaze, the glance, the practices of observation, surveillance, and visual pleasure) may be as deep a problem as various forms of reading (descipherment, decoding, interpretation, etc.) and that visual experience or "visual literacy" might not be fully explicable on the model of textuality...(Mitchell, 1994: 16).

Esta propuesta me permite observar en Eva Perón una corporalidad constituida en la interrelación lingüística y visual, es decir, inconográfica y discursiva, donde la imagen sugiere una figuración ideológica y el discurso crítico una manifestación de formas de percepción que se corresponden con códigos visuales y estados emocionales frente a una realidad cambiante. Entiendo aquí la diferencia entre imagen y figuración propuesta por Oscar Traversa (1997) en Cuerpos de papel. Figuraciones del cuerpo en la prensa 1918-1940. El crítico sostiene que en el análisis de imágenes y en la determinación del cuerpo como elemento invariante, lo importante no es preguntarse si ese cuerpo es verdaderamente de esa manera, sino interrogarse acerca de los límites sobre los que se construyen sus figuraciones. Es decir que aquello que debemos buscar en las imágenes de los cuerpos no reside en las imágenes en sí, sino en los

[...] movimiento[s] de la figuración en una zona de las prácticas sociales [...] [puesto que] [l]a figuración como tal desborda lo que comunmente llamamos imagen: en el límite, puede prescindir de ella... (Traversa, 1997: 28). 
Por esta razón, Traversa concluye que en el universo del consumo es frecuente que la figuración de los cuerpos silencie (ciegue) la imagen de éstos. Es decir que el peso subjetivo de la corporalidad acalle la presencia del cuerpo. En el caso de Eva Perón, podría decirse que la múltiple sucesión de figuraciones de su cuerpo ha transitado el camino del silenciamiento de su corporalidad y lo ha arrojado a un imaginario en el que éste solamente sirve para alojar los antagonismos ideológico-políticos que dan origen a los mitos de la santa o la megalómana. Lo que propongo es revisar su corporalidad para que recuperar el sentido dinámico de sus figuraciones como resultados de prácticas sociales y políticas inéditas en su momento.

Tomando esta formulación teórica en consideración, observo que además de los muchos otros hechos concretos en el plano económico-político, lo que realmente explica la recepción de la figura de Eva Perón es que su corporalidad surgió en un marco social, cultural y político que confirguraba una intersubjetividad en la que el cuerpo femenino proyectaba la posible inscripción de lo político. La confluencia entre pensamiento y acción aparece como un motor político que se manifiesta en una corporalidad inédita, pero con rasgos rastreables desde la cultura visual. Por eso, más que enfocarme en las retóricas verbales y visuales sobre Eva Perón que tan detalladamente identifica y analiza Valeria Grinberg Pla (2013) en Eva Perón. Cuerpo, género, nación, ofreciéndonos un exhaustivo recorrido histórico y crítico sobre su imagen, me concentro en el examen de trayectorias visuales, en los vectores que me permiten registrar y analizar la relación entre percepción visual y discurso. Planteado en palabras de Mitchell, lo que me importa es la relación dinámica entre la carga ideológica (verbal) de su corporalidad y el cimiento perceptivo y emocional (visual) de lo ideológico.

\section{Relatos visuales}

A partir de la lectura de distintas series fotográficas que muestran diversas etapas de la vida de Eva Perón, Martín Kohan y Paola Cortés Rocca (1998) han señalado con acierto que la misma Eva reconfigura su cuerpo y apariencia a medida que adquiere conciencia de su presencia en la arena política. Es cierto que el ingreso al terreno de lo político-público en su papel inicial de primera dama requería el abandono del estilo ostentoso y glamoroso hollywoodense de sus años de actriz. La adopción del traje sastre, los colores sobrios, el rodete y, principalmente, vestimenta menos reveladora de partes del cuerpo, va dejando atrás los rasgos más asociados a su vida artística, especialmente después del viaje a Europa (gira Arco Iris) de 1947. La mujer pública y política presenta un cuerpo que funciona como caja de resonancia de los reclamos sociales y como vínculo directo con un Estado que va redefiniendo sus principios democráticos. Pero también puede observarse que esta transformación 
de la corporalidad de Eva es el resultado de algo más que una férrea voluntad por ser y hacer algo en el terreno politico-social. El contexto a partir del cual Eva Perón construye su propia imagen política es el de una Argentina en la que a fines de la década del treinta la proliferación de las industrias culturales, fundamentalmente del cine y la radio, coexiste con una profunda desigualdad social.

En un extenso análisis sobre el cine argentino de las décadas del treinta y del cuarenta, Mathew Karush señala que en el contexto de creciente modernización, los sectores trabajadores y medios urbanos emplazaron en el melodrama visual los antagonismos de clase que más tarde fueron capitalizados por el discurso clasista del peronismo (Karush, 2012: 204). Mediante un extenso análisis de la filmografía del director Manuel Romero, Karush sostiene que en una coyuntura en la que proliferan imágenes e imaginarios de modernización y consumo, los conflictos sociales y de clase son presentados desde una perspectiva armonizadora. Las brechas sociales que se muestran en tropos melodramáticos clásicos, como el de la empleada doméstica abusada por el patrón o la joven rica consentida pero infeliz, son resueltos en el cine de Romero mediante el matrimonio interclase, que aparece como la herramienta de igualación de las diferencias y sobre todo como mecanismo de apaciguamiento de los conflictos.

Desde esta perspectiva, el peronismo se habría apropiado de este lenguaje de clase que si bien inicialmente remarca las diferencias sociales, en una instancia posterior las resuelve de manera armónica. Esta interpretación presenta varios problemas, entre ellos el adjudicarle al peronismo un carácter acomodaticio, impidiendo así la comprensión de las fuerzas sociales que llevaron a su surgimiento como fenómeno sociopolítico y cultural. La calificación del peronismo como una anomalía social ha reforzado marcos cognitivos dicotómicos (Vázquez, 2013), tales como los que enfrentan lo racional a lo irracional, o lo civilizado a lo bárbaro (González Stephan 2008), de raigambre en el pensamiento argentino. Estos marcos no sólo han permeado las lecturas generacionales sobre el peronismo, sino que además han obturado la visualización y comprensión de los sujetos sociales concretos que formaron parte de ese proceso de rearticulación de las demandas sociales fue la esencia de los primeros dos gobiernos peronistas (1946-1955). No obstante, recientemente se han producido trabajos que revisan ese período, tanto desde una perspectiva centrada en la historia del trabajo (Lobato, 2001), como desde miradas enfocadas en las industrias culturales (Elena, 2011; Kriger, 2009; Milanesio, 2013), en lo visual (Gené, 2005, Santoro \& Indij, 2007) y en lo emocional ( Cortés Rocca \& Kohan, 1998; Rosano, 2006, Soria, Cortés Rocca \& Dieleke, 2010; Soria 2005), que indagan los imaginarios de la época, ya sea a partir de las voces de los protagonistas o de los textos culturales que tejieron esa trama dialógica.
6. De interés sobre este tema es el análisis histórico sobre el peronismo propuesto por Alejando Horowicz, quien señala que esta fuerza política surge como resultado del impacto que tuvo el reordenamiento de la relación entre las burguesías nacionales y los sectores obreros a nivel mundial a partir de la segunda posguerra en la renta nacional de un modelo agroexportador agotado (2012). El autor propone ver el peronismo como una instancia de articulación política de la situación de trabajo de los asalariados. 
7. Tomo aquí la definición que de este concepto propone Gerard Genette en su análisis de los enunciados de ficción, los cuales contrariamente a la descripción de hechos objetivos de los enunciados de la realidad, ofrecen una descripción de un estado mental. Para el critico, el sentido literal indirecto (no figurado) de la ficción se construye a partir de "...un sentido literal que es perfectamente aceptable y posiblemente fiel a alguna realidad empírica, y cuya ficcionalidad no es en absoluto una evidencia lógica o semántica, sino más bien una probabilidad cultural, inducida por cierto número de datos convencionales de índole textual, contextual y paratextual..." (Genette, 1991: 48).
Karush sostiene que las películas de Manuel Romero que más enfatizan los antagonismos sociales proponen el matrimonio interclase como una resolución de las diferencias sociales en clave melodramática. Pero en los escenarios urbanos en los que transcurren sus historias [especialmente en Muchachas que trabajan (1938), Muchachas que estudian (1939), e Isabelita (1940) entran en contacto mujeres de diverso origen. No lo hacen solamente por medio del trabajo, sino también en otras instancias, como la pensión, el salón de lectura, las reuniones feministas, el baile, la calle, asociadas de modos menos directos a la esfera laboral, en las cuales se mezclan deseos de consumo, reivindicaciones laborales y mandatos de género. En estas zonas de contacto, sus discursos y corporalidades emergen contestando lo propuesto por Karush con respecto al matrimonio y al aprovechamiento del peronismo de un previo lenguaje de clase contestatario. Si bien es cierto que la unión interclase asimila a los sectores trabajadores, en particular a las mujeres en su papel de ángeles del hogar y de consumidoras, a los valores de los sectores medios, también es palpable que tal adopción no es el resultado de un reconocimiento de estos agentes sociales en términos institucionales legislativos, as í como tampoco de su integración en el plano del derecho constitucional. Esto explica que su potencial contestatario y la necesidad de encontrar interlocutores politicos no se agotara con el matrimonio interclase y hallara eco en las políticas impartidas por Perón cuando estaba a cargo del Ministerio de Trabajo en 1943.

Los cuerpos emergentes figurados en esas zonas de contacto entre sectores sociales en las que se comparten el deseo y el acceso al imaginario concebido y transmitido por las industrias culturales, presentan características peculiares tanto en lo ideológico como en lo visual. Las vendedoras, empleadas domésticas, pensionistas, secretarias y estudiantes de las películas de Romero exhiben una corporalidad femenina heterogénea que busca aggiornarse a los modelos impuestos por la publicidad desde la prensa gráfica, y al mismo tiempo negocian con los marcadores de clase y sus idiosincrasias. Es en esta convergencia de figuraciones del cuerpo femenino que observo una serie determinada de imágenes de Eva Perón. La recepción de su corporalidad no se explica exclusivamente por el fanatismo que despertaba el embate de sus discursos, ni por el "afecto" que despertaba con su accionar, sino por su encuadramiento en un "sensorium" o estructura de sentimientos (Williams, 1974), que prefiguraba una corporalidad femenina en la que la inscripción del accionar político directo era una "probabilidad cultural" (Genette 1993: 48)7. Las corporalidades femeninas que acogen la presencia política de Eva Perón son aquellas que emergen de ese escenario social urbano representado en las películas de Romero.

Utilizo el concepto "cuerpos emergentes", de Oscar Traversa (1997), para denominar a los cuerpos de las mujeres jóvenes y de mediana edad vendedoras, trabajadoras 
domésticas, secretarias y estudiantes provenientes en su mayoría de las provincias en búsqueda de un horizonte tradicional como el del matrimonio, pero que al mismo tiempo, por su condición de clase, han tenido que recorrer otros senderos menos cómodos. De origen social asalariado, rural y/o inmigrante, las muchachas de las películas de Romero, tienen cuerpos para el trabajo, ya sea en una fábrica (aunque este no es el escenario privilegiado por el director), en una mansión o en una tienda; es decir, cuerpos para el esfuerzo, para la resistencia a las largas jornadas y para las demandas de otros. Según Traversa (1997: 21), los cuerpos emergentes encarnan nuevos y múltiples discursos, fundamentalmente vinculados a la experiencia del trabajo urbano y el consumo, que trazan nuevos contornos físicos. Por lo tanto, las corporalidades femeninas resultan de zonas de contacto social que surgen de su relación con los productos de consumo y con distintas instancias sociales. Al mismo tiempo, la solidaridad de género está inicialmente supeditada a la solidaridad de clase frente a los abusos de los patrones; solamente cuando se traspasa la espacialidad del trabajo y se establece una distancia de resguardo y respeto, la solidaridad de género aflora como un gran movilizador de cambio social. La masividad creciente del consumo de productos de belleza femenina hace que las corporalidades investidas por todos los personajes se asemejen en ciertos aspectos, como el color de pelo, el tono del polvo de maquillaje, etc. Pero la exclusividad social de algunos productos, como pueden ser la vestimenta, el auto o los bienes domésticos se evidencia en la distancia y postura de los cuerpos con respecto a estos, así como en los discursos verbales que los refieren.

\section{Análisis:}

\section{un cuerpo, todos los cuerpos}

El cuerpo de Eva Perón emerge en este contexto y es por eso que no deja de ser percibido como fuera de lugar una vez que ingresa al mundo de las damas de beneficencia asociadas a los sectores oligárquicos y su estrato político, pues más allá de reunir los atributos de belleza aceptables dada su profesión de actriz, su corporalidad delata su condición social. De ahí que la transformación en su vestimenta haya sido interpretada con gran acierto como una estrategia para la construcción de la imagen de la mujer política. Sin embargo, es posible también observar que en verdad esa estrategia no respondía tanto a la necesidad de llevar a cabo un ajuste social en el campo de la apariencia física, sino a una forma de pensar y relacionarse con el entorno; es decir, a una manera diferente de pensar y hacer políticamente. Una fotografía de Eva Perón y Juan Domingo Perón en una parada en la ruta en una de sus giras parece señalar esto. En la escena, Perón se encuentra comiendo, parado y a gran distancia del automóvil que los traslada. En una clara situación que muestra la voluntad de mantener la intimidad del almuerzo separada del ámbito 
laboral y, sobre todo, del medio en el que su cuerpo coexiste con el del chofer que los conduce, la distancia entre el presidente y el automóvil señala una situación de estatus social.

Contrariamente, sentada hacia afuera del auto, con la puerta abierta y en actitud de diálogo, Eva come con la secretaria que los acompaña, quien viste de manera similar y al igual que ella se encuentra almorzando junto al auto. Esta distribución espacial de los cuerpos denota su cercanía con el espacio de trabajo del chofer que conduce el automóvil. La parada en el camino no parece ser para ella una instancia de retorno a la intimidad, sino un momento más de una acción determinada en la que habitan en el mismo espacio porque tienen los mismos intereses. Si la distancia entre Perón y el auto señala estatus social y jerarquía, la cercanía de las mujeres a éste indica zonas de contacto y de igualación. Allí, Eva no es ni esposa ni actriz, sino agenciadora junto a otra mujer que es su par. La corporalidad de Eva Perón es una indicación de que al nivel del imaginario social, y también en el plano de la acción, el cuerpo femenino se convierte en un locus político sin precedente en la historia argentina hasta su llegada, infundiendo en las generaciones venideras eso que Venturini llama futuralidad. Es posible pensar entonces, que lo que se busca incesantemente en las lecturas críticas y creativas de sus figuraciones constituye también una exploración sobre las formas en que el cuerpo, nuestros cuerpos, se instituyen como lugares de inscripción y de realización de lo político en el plano de lo colectivo.

En su trabajo On photography, Susan Sontag (1990) plantea que las fotografías son "experiencias capturadas" (Sontag, 1990: 14) que testimonian hechos en el campo de lo real y apelan a las emociones de quienes las observan (Sontag, 1990: 19). Las imágenes recogidas por la cámara hacen accesibles formas de conocimiento y transmiten referencias éticas y estados de conciencia. La crítica sostiene que no entendemos a partir de una fotografía, sino que aceptamos o damos por sentada la información que contiene. Para deducir o comprender, es necesario leer las fotografías en serie, idea que desarrolla en IIlness as metaphor (Sontag, 1978), donde propone que los referentes de un conjunto de fotografías no se encuentran en las imágenes en sí, sino en los procesos de producción de sentido de los cuales esas fotografías son indicios. Por eso, en esta sección del ensayo propongo observar cómo las corporalidades de Eva Perón en una serie de fotografías, especialmente la que recoge Baschetti para acompañar la edición de su registro bibliográfico, remiten a una corporalidad emergente que en su carácter agenciador convierte al cuerpo en locus político.

Este emplazamiento femenino de lo político tiene como orientación ideológica la Constitución de 1949, que promueve los derechos del niño, la ancianidad y los 
trabajadores, es decir, el campo de la acción social de la Fundación Eva Perón. La corporalidad o la iconografía de esta ideología en la que la ayuda social se transforma en un derecho constitucional se manifiesta como un vector visual que señala el contacto directo de Eva Perón con sus interlocutores. Es decir, su corporalidad, en tanto locus político llena el vacío legal y cívico creado por una concepción excluyente del Estado y de la democracia, y se manifiesta visualmente en dos instancias específicas. La primera es la que pone de relieve zonas de contacto entre ella y los niños, las mujeres, los ancianos y los trabajadores, cuyo contenido ideológico es el de la inclusión, los derechos y la capacidad de acción directa. La segunda es la del vector que está originado por la postura de su cuerpo durante los discursos políticos, especialmente sus manos, e ndica una dinámica entre pensar, sentir, decir y hacer.

De este modo, las series muestran, por un lado, una iconografía que pone de manifiesto la justicia social como el centro ideológico de la doctrina peronista, y por el otro, un credo que se exterioriza fundamentalmente en una corporalidad que como emplazamiento de lo político es accesible porque entra en contacto con los otros. En la primera instancia de la serie, que denomino "mosaico", Eva Perón está entre mineros, enfermeras, ancianos, empleados y obreros, niños y mujeres. Muchas veces se trata de una pose en conjunto, otras de un momento o acción en transcurso. Me interesa resaltar que todas aparecen como un mosaico de rostros y cuerpos, gestos y actitudes, zonas de contacto cuyos significantes no son esos mismos cuerpos, sino un claro proceso de nivelación y reconocimiento social. La racionalidad en la que se apoya la democracia, y que según Sarlo, reside precisamente en el vacío y no en el personalismo y el vínculo emocional, en estas fotografías se ve desafiada por el contacto. El cuerpo de Eva confundido con los otros se convierte en un dínamo transformador que reconoce, identifica y motiva. Opuestamente a lo que propone Sarlo, este movimiento no puede ser únicamente el resultado del personalismo y la irracionalidad de lo afectivo, sino de una inclusión que solamente es posible a partir del contacto y el reconocimiento, los cuales a su vez hacen posible la formulación del derecho.

En estos mosaicos, el baldío simbólico al que hace referencia Aurora Venturini al hablar de la infancia de Eva, se llena con la presencia y el reconocimiento de esos otros. Observadas de manera individual, las imágenes pueden inducir a reafirmar la interpretación crítica que ha visto en lo emocional el fundamento del apoyo político y social que recibió Eva Perón. Sin embargo, miradas en serie, es claro que lo emocional no es el resultado de un contacto directo basado en la dádiva, sino que es parte de una transformación social cuyos principios ideológicos se basan en el contacto y la inclusión; y su manifestación icónica es esa corporalidad emergente 
que se instala no de manera jerárquica, sino horizontal. Esto desmonta la dicotomía razón-emoción y muestra una forma de entender y hacer política cuya excepcionalidad no radica en el usufructo de los afectos, sino en la capacidad para pensar a partir de compartir el mismo plano, es decir, haciéndose carne con el otro.

En la segunda instancia, me interesa la noción de punctum propuesta por Barthes (1978), que nos permite observar trayectorias o vectores en las fotografías que retratan a Eva Perón en los actos públicos, especialmente la postura de su cuerpo frente a la audiencia de trabajadores y mujeres. Hacia la década del sesenta, el artista plástico Ricardo Carpani propuso una figuración de Eva Perón que desde lo ideológico retoma el gesto alocutorio de la Eva del micrófono y lo une a su rodete, que aparece icónicamente como la caja de resonancia de su voz. En el contexto de relectura del peronismo por parte de la juventud de los sesenta y setenta, y de la reconfiguración al interior de algunos sectores sindicales, mostrarla en el gesto movilizador de su habla sirve de refuerzo para la radicalización y el giro ideológico hacia la izquierda dentro del peronismo. Esta figuración deja de lado la postura de sus manos en los discursos públicos.

En distintas series se observa que la posición hacia arriba de las palmas de las manos reemplaza el gesto acogedor que vemos en sus saludos desde el tren sanitario o desde el balcón, semejantes a los de Juan Perón. Las palmas hacia arriba y los dedos en posición plegada asemejan dos palancas que parecen empujan a esa audiencia. De esta manera, su cuerpo aparece como un motor, una fuerza propulsora, más que como dínamo. Observadas individualmente y enfocándonos en la experiencia que testimonian, las imágenes muestran el siguiente vector de recorrido descendente: rodete, perfil, boca, micrófono, brazos extendidos, manos en forma de palanca, dedos semi-plegados, cabezas, rostros de la audiencia y cuerpo multitudinario. Si en la composición mosaico lo que prima es una corporalidad de Eva Perón que no silencia su imagen, en la instancia del vector, la corporalidad se agiganta tanto como se expande el eco sonoro de su voz.

Opuestamente a lo señalado por Traversa con respecto a las figuraciones publicitarias que silencian o ciegan a la imagen del cuerpo, en este caso la figuración del vector vista en serie es potenciadora de la imagen de una corporalidad no solamente entregada a la acción, sino también movilizadora de los otros. Su cuerpo es la manifestación de un becoming, una transformación que no tiene otro objeto que el de movilizar a aquellos a quienes se dirige. Como señala Marysa Navarro

[...] ella era la encargada de poner en marcha las tácticas, explicar y repetir la doctrina ante los más diversos auditorios, innovar en 
cuanto sus obras fueran un complemento de las conquistas obtenidas [...] mantener el nivel de movilización de las masas, pero también su control, y en nombre de éstas, hostigar al enemigo y asegurar que las transformaciones sociales iniciadas en 1943 se profundizaran y ampliaran (Navarro, 1997: 347-348, apud Grinberg Pla, 2013: 218).

Esta noción de vector nos remite a la metáfora del motor para referirnos a una corporalidad generadora de movimiento. Se trata de un cuerpo que pone en marcha a otros, por lo que su corporalidad, dada por el rodete, la boca, el gesto de la alocución, el micrófono, los brazos estirados y las manos como palancas nos habla de un locus político en el que el cuerpo es habitado en la medida en que se lo pone en marcha o se lo entrega a la causa, la cual consiste en la transformación de las necesidades sociales en derechos.

Sin duda, la obra del artista plástico Daniel Santoro es una de las más frecuentemente estudiadas y referidas en cuanto a la representación del peronismo y Eva Perón reciente. Probablemente, uno de los aspectos que más interesen de su obra, especialmente de Manual del niño peronista (2002) y y Perón mediante (2008), sea la representación de lo que se ha denominado "política del sentimiento" (Soria, Cortés Rocca \& Dieleke, 2010) en el ámbito de los estudios culturales que se abocan al peronismo. Estas perspectivas señalan la naturaleza afectiva del vínculo entre Eva Perón y los sectores populares, y destacan una vez más su papel conector entre el pueblo y el peronismo. Susana Rosano ha señalado que Santoro

[...] construye una mirada singular, propia, sobre la mitología del movimiento. La manera en que Santoro revisita la iconografía de los años cuarenta y cincuenta se produce a partir de una selección de imágenes que privilegia aquellas estampas alegóricas y apasteladas del libro La Argentina justa, libre y soberana... (Rosano, 2010: 243).

La corporalidad de Eva que recupera Santoro en sus escenarios de bienestar social y de obra pública, remite a su actividad en la Fundación: la mujer que viste el traje sastre y lleva rodete, pero cuyo nervio político no se manifiesta en el dedo índice de los discursos en el balcón, sino en la palma protectora y en la mano que entrega desde guardapolvos y juguetes, hasta máquinas de coser. De esta manera, en su iconografía del peronismo, Santoro reafirma la conexión entre emoción y Estado que ha sido señalada en relación con la política social de Eva Perón a través de la Fundación y otras instancias públicas. Esta es una corporalidad "tosca", maternal, que figura un cuerpo totalmente dedicado al hacer y, sobre todo, al proveer; es decir, un cuerpo agenciador que se asocia a los sueños utópicos de un
8. Este volumen reúne imágenes de sus muestras "Un mundo peronista" (2000) y "Evita, la lejana patria de la felicidad". 
[...] Estado protector populista, a los que Santoro considera un verdadero paraíso perdido, un momento de la historia nacional en el que la felicidad del pueblo parece posible... (Rosano, 2010: 244).

En las pinturas Eva tapa al niño y lo tapa con la manta, Eva y los niños y Evita protege al niño peronista, la representación del cuerpo de Eva como un locus político está impregnada de la estética monumentalista y neoclacisista que es acorde tanto con la visión personal del propio Santoro, como con lecturas críticas de la iconografía peronista (Gené, 2005) y remarcan la representación del Estado protector. No obstante, Santoro le da un giro que nos permite comprender visualmente a Eva Perón más allá de la figura protectora. Como bien señala Rosano a partir de las propias palabras de Santoro, la representación maternal de Eva es central en su visión actualizada del peronismo. Al respecto, el artista plástico señala:

Lo que intento con la figura de Eva Perón es una especie de arquetipo que sería como la madre Estado. El Estado maternal. Sería una nueva categoría que sería un invento del peronismo, y Eva Perón lo encarnó en cierto modo, a través de las obras que hizo...desde la Fundación a un montón de cosas más [...] Esa Madre-Estado se contrapone al Estado paternalista, fruto del Estado liberal [...] En cambio, el Estado maternal es ese Estado sensible que se hace cargo de los desamparados. Y restituye la justicia social. Eva Perón piensa en una república para los niños, pero en realidad no es para todos los niños, es para los niños que no tienen padres. Y piensa en cada una de las situaciones en las que el Estado debe hacerse presente. Por eso hablo de un Estado maternal (Santoro, 2001: 10, apud Rosano 2010: 245).

Esta noción de Estado-maternal representado en el cuerpo de una Eva con traje sastre y rodete, como la de los discursos, pero menos combativa y con un cuerpo menos delgado y más matronal, más nutricio que movilizador, demuestra lo explicitado por Santoro con respecto a los destinatarios de las obras de la Fundación. Al mismo tiempo, este rasgo remarca lo señalado en la serie "mosaico" con respecto a la igualdad y la inclusión sugeridas por las zonas de contacto físico. En las pinturas de Santoro, los niños en guardapolvo escolar tienen casi las mismas dimensiones que el cuerpo de Eva. Tal engrandecimiento puede observarse como un indicador visual del proceso de igualación e inclusión social.

Aunque es obvio que aquellos sectores históricamente excluidos por la ausencia de políticas públicas redistributivas eran el objetivo de sus acciones directas, el alcance de estas no se agotaba en sus destinatarios primeros, puesto que los trascendía al plasmar la ayuda social en el campo del derecho. La relación desproporcional 
entre los cuerpos de los niños y el de Eva Perón, que agiganta a los primeros con respecto a la segunda, en pinturas como Evita protege al niño peronista, El hada buena argentina, El guardapolvo nuevo, entre otras, señala el impacto de su figura en el imaginario. Del mismo modo, en pinturas como La felicidad del pueblo, el tamaño de los retratos de Eva Perón en el chalecito del barrio obrero escapan a la escala, indicando entonces la dimensión de su presencia en el imaginario de los sectores asalariados. A primera vista, lo emocional aparece evidenciado en el carácter devocional de esta presencia. Sin embargo, también puede observarse que lo emocional está relacionado con el tema del derecho y la inclusión que son posibles por medio de la presencia de ese cuerpo "tosco", como en su momento lo calificó Ghioldi en $1952^{9}$.

La crítica y la ficción se han nutrido del discurso reaccionario sobre el peronismo y la figura de Eva Perón y han contribuido a la solidificación de un imaginario en el que su corporalidad se encuentra figurada como un amar dando, más que como un pensar haciendo. La noción de que la ayuda social que corporalizó fue la base de los principios y derechos de la Constitución de 1949 queda excluida del discurso crítico desde el cual una y otra vez se vuelve a proponer su figura como ejemplo de la manipulación afectiva. La proyección en el imaginario social de los derechos a la ancianidad, del niño y del trabajador como resultado de una transformación cuya base es la acción y la ayuda social guarda íntima relación con las dos instancias visuales de la corporalidad de Eva, el mosaico y el vector, y llena de significación el vacío o baldío institucional sobre el que muchas veces descansa una concepción disfuncional y restrictiva de la democracia.

La serie de imágenes mosaico unen en el imaginario la proyección de sujetos sociales en plena transformación de su condición y lugar en la sociedad. Retomando el análisis de Oscar Traversa sobre los cuerpos en la prensa gráfica de las décadas del treinta y del cuarenta, es decir, del contexto del cual surge la misma Eva, la transformación de su propio cuerpo -que es aquello que Cortés Rocca y Cohan (1998: 215) entienden como la construcción que ella misma hace de la mujer política al pasar del vestido al traje sastre, y de la melena al rodete -, no es únicamente una estrategia para reacomodar su figura a la instancia presidencial de Perón, sino que constituye un giro esperable de eso que Traversa entiede como cuerpos geométricos. Las figuraciones del rostro y de la corporalidad de Eva Perón que surgen de la serie mosaico, señalan una ruptura con esas figuraciones del cuerpo femenino de la prensa de los treinta y cuarenta, que modelan o son portadores de ropa y productos de belleza, y cuyos rostros y miradas se pierden en un horizonte anónimo. Si hay algo que distingue a esta serie es la presencia tanto de su mirada como la de aque-
9. Américo Ghioldi

la describió como "...tosca, con voluntariosa energía, dominadora ambición y gusto por manejar hombres, cosas que fueron cultivadas por el Estado..." (Ghioldi, 1952: 45, apud Pla, 2013: 172) 
Ilos que la acompañan y componen un todo. De este modo, el horizonte infinito que casi por definición distingue la mirada del cuerpo en pose (Traversa, 1997: 215) es reemplazado por un conjunto de corporalidades que comparten en ese horizonte un sentido de reconocimiento.

\title{
Conclusión
}

\author{
"La sombra de Esa Mujer estaba pegada \\ en mi piel, yo era ella... \\ La sombra de Esa Mujer se me hizo luz." \\ Venturini (2014: 94).
}

¿Es la corporalidad de Eva Perón una manifestación del personalismo autoritario o del continuum histórico de un imaginario en el que el cuerpo femenino como locus político se proyectaba como una probabilidad cultural (una corporalidad agenciadora) o como una futuralidad? ¿Podemos pensar sus figuraciones actuales como prismas a partir de los cuales mirar el pasado y el futuro de la relación entre cuerpos y política? Si consideramos que las imágenes no sólo no son fieles reflejos de algo real, ni aparecen en nuestro cerebro como la reproducción de un negativo, sino que son la síntesis de un conjunto de réplicas a nivel mnémico, deductivo y sensorial, no solo de ese negativo, sino también de lo que está fuera de encuadre, la persistente exploración de la corporalidad de Eva Perón nos sugiere que aquello que se encuentra en permanente indagación es la historia de nuestra forma de mirar y de vernos a nosotros mismos ante nuevas dinámicas políticas y sociales.

El cuerpo y la corporalidad de Eva no son el resultado de una férrea voluntad individual por ingresar al terreno de la política, sino el signo de un proceso social, politico y cultural de articulación de las demandas de los sectores más desfavorecidos de la sociedad. Es probable que la incomodidad que representa su cuerpo no se deba ni a la estridencia de su voz, ni a su supuesta desmesurada emocionalidad, sino a la materialización de las prácticas restrictivas de la democracia denuniadas por su gestualidad agenciadora. La disonancia de su corporalidad no se explica en los misterios que encierra su cuerpo, sino en los procesos sociales que ella encarna y revela. Este enfoque nos permite visualizar unos referentes que no remiten directamente a su cuerpo, sino a los procesos sociales, politicos y culturales por los cuales éste se constituyó como un emplazamiento de lo político, emblema de la militancia para unos, repudiado y oscuro objeto de deseo para otros. Es decir, la lectura de la serie de figuraciones visuales de Eva Perón, nos permite comprender una forma de construcción de la corporalidad que trasciende al personaje histórico. 
El interés por su figura deja entonces de tener explicación en los aspectos exclusivos de su apariencia física y se transforma en una cuestión sobre las formas en que su corporalidad fue la caja de resonancia de otras corporalidades pasadas, presentes y futuras. Será por esto, tal vez, que continuamos mirándola y oyéndola; porque no es su cuerpo el que esconde secretos, sino su corporalidad la que no deja nunca de revelarnos la historia de las miradas desde las que concebimos lo que fuimos, lo que somos, y lo que quizá lleguemos a ser. Podría decirse entonces que no es Eva Perón, ni su imagen, ni sus figuraciones las que evidencian una naturaleza diferente, sino que es el carácter inédito de las prácticas sociales que su cuerpo encarnó, llenando de corporalidad a las generaciones posteriores, aquello que continúa sonando con disonante (y curiosa) estridencia.

Abstract: This essay analyzes images and representations of Eva Perón combining theories of corporeality and affection with theories of the photo-image proposed by WJT Mitchell, Roland Barthes and Susan Sontag. It aims to revise the myths related to Eva Perón and her physical and emotional representations, from the perspective of an analysis of her corporeality and her relation with the pre-peronist imagery around women, politics, beauty and consumerism.

Keywords: Eva Perón, myth, policy, beauty, Argentina.

\section{Referencias}

BARRY, Carolina. Eva Perón y las primeras dirigentes del peronismo, 1949-1955. Historia y Política, v. 26, p. 227-257, Jul.-Dic. 2011.

BARTHES, Roland. Image, music, text. New York: Hill and Wang, 1978.

BARTRA, Roger. La batalla de las ideas y las emociones. In: MORAÑA, Mabel; SÁNCHEZ PRADO, Ignacio (Eds.). El lenguaje de las emociones. Afecto y cultura en América Latina, p. 17-36. Madrid: Iberoamericana Vervuert, 2012.

BASCHETTI, Roberto. Eva Perón. Registros bibliográficos. Buenos Aires: Biblioteca Nacional Mariano Moreno, 2013.

CORTÉS ROCCA, Paola; KOHAN, Martín. Imágenes de vida, relatos de muerte. Eva Perón: cuerpo y política. Rosario: Beatriz Viterbo Editora, 1998.

ELENA, Eduardo. Dignifying Argentina. Peronism, citizenship, and mass consumption. Pittsburgh: University of Pittsburgh, 2011. 
GENÉ, Marcela. Um mundo feliz, imágenes de los trabajadores en el primer peronismo 1946-1955. Buenos Aires: Fondo de Cultura Económica de Argentina, 2005.

GENETTE, Gerard. Ficción y dicción. Barcelona: Editorial Lumen, 1993.

GONZÁLEZ-STEPHAN, Beatriz. Saberes tecnológicos y cuerpos (pos)coloniales: Martí en la escena norteamericana. In: BOLAÑOS, Alvaro F.; NICHOLS, Geraldine C.; SOSNOWSKI, Saúl (Eds.). Literatura, política y sociedad: Construcciones de sentido en la Hispanoamérica contemporánea. Homenaje a Andrés Avellaneda, p. 77-98. Pittsburgh: Instittuto Internacional de Literatura Iberoamericana, 2008.

GRINBERG PLA, Valeria. Eva Perón. Cuerpo, género, nación. Costa Rica: Universidad de Costa Rica, 2013.

HOROWICZ, Alejandro. Los cuatro peronismos. Buenos Aires: Edhasa, 2011.

ILLOUZ, Eva. Why love hurts. A sociological explanation. London: Polity, 2012.

- Cold intimacies. The making of emotional capitalism. Cambridge: Polity, 2007.

- Consuming the romantic utopia: love and the cultural contradictions of capitalism. Berkeley: University of California Press, 1997.

KARUSH, Matthew B. Culture of class. Radio and cinema in the making of a divided Argentina, 1920-1946. Durham: Duke University, 2012.

KRIGER, Clara. Cine y peronismo. Buenos Aires: Siglo Veintiuno Editores, 2009.

LINDEN, David. Touch: the science of hand, heart, and mind. New York: Pinguin Books, 2016.

LOBATO, Mirta Zaida. La vida en las fábricas. Trabajo, protesta y política en una comunidad obrera, Berisso, 1904-1970. Buenos Aires: Prometeo, 2001.

LÓPEZ-IBOR ALIÑO, J. J. El cuerpo y la corporalidad. Madrid: Gredos, 1974.

MERLEAU-PONTY, Maurice. Phenomenology of perception. New York: Routledge, 2002.

MILANESIO, Natalia. Workers go shopping in Argentina. The rise of popular consumer culture. Alburquerque: University of New Mexico, 2013.

MITCHELL, W. J. T. Picture theory. Chicago: The University of Chicago, 1994.

MONTENEGRO MEDINA, María Angélica; ORNESTEIN LETELIER, Claudia; TAPIA 
ILABACA, Patricia Angélica. Cuerpo y corporalidad desde el vivenciar femenino. Scielo, v. 12, n. 2, p. 165-168, 2006.

NAVARRO, Marysa (Comp.). Evita. Mitos y representaciones. Buenos Aires: Fondo de Cultura Económica, 2002.

ROSANO, Susana. Apuntes para pensar la obra de Daniel Santoro. El paraíso perdido del peronismo en clave hermética. In: SORIA, Claudia; CORTÉS ROCCA, Paola; DIELEKE, Edgardo (Eds.). Políticas del sentimiento. El peronismo y la construcción de la Argentina moderna, p. 241-253. Buenos Aires: Prometeo Libros, 2010.

- Rostros y mascaras de Eva Perón. Imaginario populista y representación. Rosario: Beatriz Viterbo Editora, 2006.

SANTORO, Daniel; INDIJ, Guido. Perón mediante. Buenos Aires: La Marca Editora, 2007.

SARLO, Beatriz. La passion y la excepción. Buenos Aires: Siglo XXI, 2003.

SONTAG, Susan. On photography. New York: Doubleday, 1990.

. Illness as metaphor. New York: Farrar, Strauss and Giroux, 1978.

SORIA, Claudia; CORTÉS ROCCA, Paola; DIELEKE, Edgardo (Eds.). Políticas del sentimiento. El peronismo y la construcción de la Argentina moderna. Buenos Aires: Prometeo Libros, 2010.

THRIFT, Nigel. Intensities of feeling: towards a spatial politics of affect. Geografiska Annaler, "Series B. Human Geography", v. 86, n. 1, p. 57-78, Special issue: the political challenge of relational space, 2004.

TRAVERSA, Oscar. Cuerpos de papel. Figuraciones del cuerpo en la prensa 19181940. Barcelona: Gedisa, 1997.

VÁZQUEZ, Karina Elizabeth. Aprendices, fabriqueras y obreros. El trabajo industrial en la narrativa argentina del siglo XX (1930-2007). Buenos Aires: Editorial Biblos, 2013.

VENTURINI, Aurora. Eva Alfa y Omega. Buenos Aires: Sudamericana, 2014.

WILLIAMS, Raymond. Television: technology and cultural form. "Technosphere Series". London: Collins, 1974. 